\title{
Evaluation of Enterprise Information Architecture (EIA) Practices in Malaysia
}

\author{
Rafidah Abd. Razak, Zulkhairi Md. Dahalin, Rohaya Dahari, Siti Sakira \\ Kamaruddin and Sahadah Abdullah \\ Faculty of Information Technology, Universiti Utara Malaysia, 06010 UUM Sintok, Kedah, \\ Malaysia \{rafidah,zul,roha, sakira,sahadah\}@uum.edu.my
}

\begin{abstract}
In this paper, we described findings based on a study on Enterprise Information Architecture (EIA) implementation in Malaysia. The study investigates the existence of the enterprise architecture in private and public enterprises in Malaysia and evaluates the presence of the architecture and its practical use against the established guidelines and frameworks as expounded by the proponents of the enterprise architecture. The Zachman Framework was used to evaluate the practice of EIA in these enterprises. A multiple case study was undertaken in which ten enterprises from public and private sectors participated. The paper would highlights gaps in the current practices of EIA in Malaysian enterprises and identifies factors of EIA implementation. In addition, the study would also provide recommendations for enterprises to consciously embark on the EIA paradigm in order to achieve the goals of the enterprise.
\end{abstract}

Keywords: Enterprise Information Architecture, Enterprise Architecture, Zachman Framework

\section{INTRODUCTION}

Enterprise Information Architecture (EIA) is a blueprint for how an organization achieves the current and future business objectives using information technology (IT). It examines the key business, information, application, and technology strategies and their impact on business functions [1]. The Zachman Framework is probably the most recognized and popular approach to enterprise modeling [2]. The framework is described as an architecture that represents the information systems' artifacts, providing a means of ensuring that standards for creating the information environment exist and that they are appropriately integrated.

The increasing size and complexity of the implementation of information systems, it is necessary to use some logical construct for defining and controlling the interfaces and integration of all of the components of the system [3]. Therefore, it is necessary to any enterprise to define enterprise information architecture to enable an integrated vision and global perspective of the enterprise information resources; to enable the discovery and elimination of redundancy in business process; to having information systems that reflect common goals and performance measures for all managers, to encourage cooperation within enterprise; and to become the bridge between the business and technical domains [1].

Please use the following format when citing this chapter:

Razak, R. A., Dahalin, Z. M., Dahari, R., Kamaruddin, S. S., Abdullah, S., 2007, in IFIP International Federation for Information Processing, Volume 255, Research and Practical Issues of Enterprise Information Systems II Volume 2, eds. L. Xu, Tjoa A., Chaudhry S. (Boston: Springer), pp. 1011-1017. 

and Sahadah Abdullah

As Malaysia moved from an agriculture-based to a manufacturing-based and presently towards capital-intensive, high technology and high value-added industries, defining and planning for strategic information is becoming very important to Malaysian enterprises. For this reason, we felt that it would be crucial to investigate the situation in Malaysia, in order to gain insight into actual EIA implementation in Malaysian enterprises. The findings could promote the awareness of EIA implementation in terms of lessons learnt, pitfalls, contributing factors and benefits. In addition, the study could provide recommendations for enterprises to embark on ElA implementation.

To address these concerns, the research described in this paper was designed around the following three main objectives:

(1) to investigates the existence of the enterprise architecture in private and public enterprises in Malaysia; (2) to evaluates the presence of the architecture and its practical use against the Zachman Framework; and (3) to provides recommendations for enterprises to consciously embark on the EIA paradigm based on the identifies factors in order to better align the whole organizations' IT adoption and information requirements fit nicely into its business strategies.

The Zachman Framework was used as the theoretical foundation for acquiring the necessary knowledge about EIA implementation in this study. The Zachman Framework begins with the planner's perspective, followed by the owner's perspective, the designer's perspective, the builder's perspective and the subcontractor's perspective. Each of the leveled view corresponds to the six dimensions of the architectures, i.e. data, function, network, people, time and motivation $[1,4]$.

However, the respondents interviewed in this study were mainly the IS Planning analysts or the person(s) responsible for developing the enterprise's IT master plan. We viewed this as the equivalent of Zachman's three top perspective (planner, owner, and designer) and Spewark [4] EA planning. Therefore, the results discussed in this paper will focus with only these perspectives.

\section{RESEARCH METHOD}

The research described here follows the case study method. The study consists of three main steps. Basically, step 1 involved developing theory, selecting cases, and designing data collection protocol. Step 2 started with conducting case study based on the selected cases in step 1 and then writing an individual case report. In step 3, crosscase analyses for all the cases were drawn. Thereafter, suggestions were made based on the patterns established in the cross-case analysis.

Case study is used in many situations, some of which are organizational and management studies [5]. Case study research can be positivist, interpretive, or critical, depending upon the underlying philosophical assumptions of the researcher. In our study, we have adopted interpretive in-depth case study research because we want to explore in-depth about EIA in the chosen enterprises.

In this study, a multiple case study approach was chosen because of the need to explain the implementation of EIA in the enterprises in Malaysia. The evidence from 
multiple cases is often considered more compelling and robust [5]. Ten enterprises from public and private sectors participated in the study. The study used the Zachman Framework as a theoretical base in a structured way for acquiring the necessary knowledge about enterprises with respect to the EIA. The unit of analysis is the department responsible for planning the enterprises' IS usage and IT adoption. A case study protocol was constructed to help facilitate investigation and fact-findings to ensure consistency across multiple cases. Techniques of data gathering that were used are interviews, documentation and questionnaires.

The interviews were recorded and transcribed, and scripts were returned to the interviewees to ensure validity of responses. Questionnaires were distributed to key user representatives for cross validation and intra-organizational consistency. Documentations such as annual reports and the enterprise's business strategies were analyzed to determine the enterprise's motivations, concerns, and performance indicators.

The Zachman Framework was used to evaluate the practices of EIA in the study. Pattern-matching technique was used to analyze the data and factors of EIA implementation were based on the feedback received from the individual cases.

\section{RESULTS AND DISCUSSION}

The results and discussion will be presented in the following sections. Section 3.1 will provide background profiles of the cases and will also discuss the EIA practices of the enterprises in the study. Section 3.2 will evaluate the practices against the Zachman Framework. Section 3.3 will discuss on the factors of EIA implementation interpreted from feedback received from the cases.

\subsection{Background Profiles of the Cases and the EIA Practices}

The profiles of the case study are presented in Table 1.

Table1. Profiles of the Cases in the Study

\begin{tabular}{cccccc}
\hline & $\begin{array}{c}\text { Type of } \\
\text { business }\end{array}$ & $\begin{array}{c}\text { No. of } \\
\text { employees }\end{array}$ & $\begin{array}{c}\text { IT } \\
\text { dept }\end{array}$ & Respondents Job Title & No. of IT staff \\
\hline Case 1 & Gov't & 200 & yes & IS Officer & 36 \\
Case 2 & Gov't & 500 & yes & IS Officer & 17 \\
Case 3 & Private & 935 & yes & IT Manager & n/a \\
Case 4 & GLC & 7000 & yes & Deputy Director & 95 \\
Case 5 & GLC & 4000 & yes & SA & 130 \\
Case 6 & Gov't & 714 & yes & IT Officer & 4 \\
Case 7 & Private & 1200 & yes & Vice President & 27 \\
Case 8 & Private & 200 & yes & Senior Manager & 200 \\
Case 9 & Gov't & 500 & yes & Director, SA & 23 \\
Case 10 & GLC & 1300 & yes & AGM & 26 \\
\hline
\end{tabular}


1014 Rafidah Abd. Razak, Zulkhairi Md. Dahalin, Rohaya Dahari, Siti Sakira Kamaruddin and Sahadah Abdullah

For reasons of confidentiality, the cases' names are presented anonymously. All the enterprises have a formal IT department. Four of the enterprises represent the government sector (Gov't), three represent government link companies (GLC) and the remaining four are from the private sector. In terms of size, the sample belongs to the medium to large enterprises and they are situated in various cities in Malaysia.

Table 2. EIA Practices in the Enterprises

\begin{tabular}{|c|c|c|c|c|c|c|}
\hline & Plan & $\begin{array}{c}\% \\
\text { Imple } \\
\text { mente } \\
\mathrm{d}\end{array}$ & Review & Planning scope & $\begin{array}{l}\text { Frequency of } \\
\text { Planning }\end{array}$ & $\begin{array}{c}\text { Planning time } \\
\text { frame }\end{array}$ \\
\hline Case 1 & Formal & $80 \%$ & Quarterly & Enterprise-wide & Yearly & 3 months \\
\hline Case 2 & Formal & $87 \%$ & Yearly & Enterprise-wide & 5 years & 12 months \\
\hline Case 3 & Formal & $20 \%$ & Yearly & Enterprise-wide & 5 years & 7 months \\
\hline Case 4 & Formal & $50 \%$ & Yearly & Enterprise-wide & 5 years & 10 months \\
\hline Case 5 & Informal & $90 \%$ & Halfyearly & Enterprise-wide & Yearly & 12 months \\
\hline Case 6 & Formal & $80 \%$ & Yearly & Enterprise-wide & Yearly & 12 months \\
\hline Case 7 & Informal & $75 \%$ & $\begin{array}{c}\text { No because } \\
\text { short-term } \\
\text { project }\end{array}$ & Enterprise-wide & Yearly & no \\
\hline Case 8 & Formal & $90 \%$ & Yearly & Enterprise-wide & 5 years & 3 months \\
\hline Case 9 & Formal & $20 \%$ & Yearly & Enterprise-wide & Yearly & 2 months \\
\hline Case 10 & Formal & $70 \%$ & Yearly & Enterprise-wide & 7 years & 6 months \\
\hline
\end{tabular}

All ten enterprises conduct EIA planning with eight formal and two informal planning. In terms of the rate of successful implementation (Table 2), with the exception of Case 3 and Case 9, the rest of the enterprises have between $50 \%$ to $90 \%$ rate of implementation. Both Case 3 and Case 9 implemented $20 \%$ of its implementation, which is considered too low. The scope of planning is enterprise wide as indicated in all cases.

Reviews are conducted quarterly, half yearly or yearly except for Case 7 because of short term projects. A closer examination of Case 7's requirements shows that instead of periodic reviews, they would prefer those personnel involved to accumulate requirements through post-mortem sessions and bring these forward to the next exercise conducted yearly. This would ensure current their planning and implementations run smoothly and are not hindered by new and additional requirements along the way.

In terms of frequency of planning, some enterprises conduct regular short term (yearly) planning whilst others prefer long term planning between five to seven years. The planning time frame ranges between two months to twelve months. However, Case 7 is the only case that did not address planning time frame. 


\subsection{Cross Case Analysis}

Data from the findings are then map against the Zachman Framework. The results show a mix pattern of practices in various dimensions. In terms of EIA practice, the findings found that all ten organizations conduct variations of EIA, particularly at the planning level. This is equivalent to the Planner perspective in the Zachman Framework.

Table 3. Zachman Framework Planner Perspective

\begin{tabular}{|c|c|c|c|c|c|c|}
\hline & $\begin{array}{c}\text { Data } \\
\text { (Subj Areas) }\end{array}$ & $\begin{array}{l}\text { Function } \\
\text { (Bus. Fns) }\end{array}$ & $\begin{array}{c}\text { Network } \\
\text { (Loc.) }\end{array}$ & $\begin{array}{c}\text { People } \\
\text { (Env. Elem) }\end{array}$ & $\begin{array}{c}\text { Time } \\
\text { (Events) }\end{array}$ & $\begin{array}{l}\text { Motivation } \\
\text { (goals } \\
\text { /strategies) }\end{array}$ \\
\hline Case 1 & In-house & In-house & In-house & Involved & & Involved \\
\hline Case 2 & In-house & In-house & Outsource & Involved & & Involved \\
\hline Case 3 & In-house & In-bouse & In-house & Involved & & Involved \\
\hline Case 4 & In-house & In-house & In-house & Involved & & Involved \\
\hline Case 5 & In-house & In-house & Outsource & Involved & & Involved \\
\hline Case 6 & Outsource & Outsource & Outsource & Involved & & Involved \\
\hline Case 7 & In-house & In-house & In-house & Involved & & Involved \\
\hline Case 8 & In-house & In-house & In-house & Involved & & Involved \\
\hline Case 9 & Outsource & Outsource & Outsource & Involved & & Involved \\
\hline $\begin{array}{c}\text { Case } \\
10\end{array}$ & Outsource & Outsource & Outsource & & & \\
\hline
\end{tabular}

A number of the enterprises also outsourced their EIA planning whilst a small number carried out EIA planning informally. Data, Function and Network dimensions appeared to be the common dimensions implemented across all ten cases. This suggests that these three dimensions represent the architectures and models practiced currently by many organizations, from planning right down to the design and implementation stages.

On the extent of the EIA practices based on the mapping of the Zachman's EIA framework, most of the EIA work focused on all dimensions except for TIME across all perspectives. Whilst ELA planning is carried out and is evidenced in all ten cases. Majority of the enterprises prefer to conduct in-house EIA activities at the DATA and FUNCTION dimensions from the PLANNER perspective.

However, for organizations that do outsourcing, PEOPLE dimension is usually given less emphasis. TIME dimension is not addressed in almost all perspectives particularly at the higher level such as PLANNER and OWNER perspectives and to a lesser extent, the DESIGNER perspective. Experience of the researchers found that the TIME dimension was the least understood.

The need to align IT adoption to the business strategy is clearly evidenced from involvement of majority of the cases in the higher level perspectives namely, PLANNER, OWNER and DESIGNER. However, this was not adequately addressed in the lower level perspectives namely, BUILDER and SUB-CONTRACTOR due to the limitation of the study respondents interviewed for the study. 

and Sahadah Abdullah

\subsection{Factors of EIA implementation}

Based on the interpretations from the respondents' feedback, the factors that contribute to EIA practices were identified. Top management support is an important factor identify by the respondents for the success of EIA implementation. This is closely related to adequate budget allocation, which is the next contributing factor identified. Respondents have been consistent in stressing the importance of funding for the EIA project, which too often have been overlooked as the project is assumed to be part of the IT procurement process.

The next contributing factor is the existence of a formal structure for the EIA project management and the existence of proper documentation procedure. Good project management will help ensure timely project completion and ability to achieve optimal human and financial resources.

Another contributing factor to EIA practice is favorable work environment that facilitates collaboration between work groups, adequate facilities and infrastructure for IT adoption, stable and consistent policies, and an environment that facilitates ease of work.

Human resource has also been identified as an important factor for EIA practice. Staff turnover, incompetent IT staff, lack of user commitment, shortage of expertise to carry out EIA, unclear user requirements, conflict of understanding between EIA team and management, and inadequate staff make up the human resource factor that need to be addressed before implementing EIA.

Other contributing factors which equally important are atmosphere that encourages creativity and innovativeness, there is a need for management and users to be creative and innovative in contributing ideas so that new processes, products and services can be created to increase productivity and become more competitive. Adequate time and training, technology impact analysis, and IT planning were also identified as contributing factors.

\section{CONCLUSIONS}

This paper has reported on EIA implementation based on the assessment of IS Planner or the person(s) responsible for developing the enterprise's IT master plan. The Zachman Framework was used to evaluate the practice of EIA in ten enterprises. A multiple case study was undertaken in which enterprises from public and private sectors participated. The purpose was to address the following objectives:

(1) To investigates the existence of the enterprise architecture in private and public enterprises in Malaysia;

(2) To evaluates the presence of the architecture and its practical use against the Zachman Framework; and

(3) To provide recommendations for enterprises to consciously embark on the EIA paradigm based on the factors identifies, in order to achieve the goals of the enterprises. 
In response to the first objective, the findings found that all ten enterprises conduct variations of EIA, particularly at the planning level. This is called the Information Strategy Planning (ISP) or IT planning, with none of the participating enterprises made references to any framework. This may suggest that the idea of EIA is relatively new in Malaysia.

However, we found, in regard to the second objective, this study gives a general outlook of EIA implementation in the selected cases, which could be incomplete or not adequately addressed yet in this study. Nevertheless, the study discovered that there is a poor knowledge and understanding of EIA among the enterprises though there had been efforts at implementing EIA focusing on the Data, Function and Network architectures. Future studies should look into formalizing the enterprise architecture based on the perspectives of the Planner, Owner, Designer, Builder, and Sub-contractor.

Based on the interpretations of identified factors from respondents' feedback the factors that contribute to EIA implementation were identified. Among the factors identified were Top Management Support, Budget Allocation, Project Management, Work Environment, Human Resource, R\&D, Time, Training, Documentation, and Outsourcing. In our future extension of the study we plan to examine the factors in greater details.

The research findings presented in this paper was exploratory in our attempt to gain an insight of the EIA practices in Malaysia. The findings derived from the study are specifically limited to the cases in the study and therefore may not represent the whole picture of the EIA implementation in Malaysia. Our view as researcher is that we need to examine the EIA implementation from various perspectives starting from the top of the organizations to the bottom in order to get the real picture.

However, it is our hoped that the results of this study can be used by the government and private sectors to formulate policies and guidelines on enterprise architecture so that the enterprise's IT adoption and information requirements fit into its business strategy.

\section{REFERENCES}

1. C.M. Pereira and P. Sousa, Enterprise Architecture: Business and IT Alignment (the SAC '05, Santa Fe: NM, USA, 2005).

2. G.R. Khoury and S.J. Simoff, Enterprise Architecture Modelling using Elastic Metaphors, in Proc. of First Asia-Pacific Conference on Conceptual Modelling (APCCM 2004) (Dunedin, New Zealand, 2004), pp.65-69.

3. J. Zachman, A Framework for Information Systems Architecture, IBM Systems Journal. Volume 26, Number 3, (1987).

4. S.H. Spewak, Enterprise Architecture Planning: Developing a Blueprint for Data, Applications and Technology (QED Publishing Group: Princeton, NJ, 1992).

5. R.K. Yin, Case Study Research - Design and Methods (Volume 5) (Sage Publications: Newbury Park, 1984). 